Article

\title{
Impact of Spanish Offshore Wind Generation in the Iberian Electricity Market: Potential Savings and Policy Implications
}

\author{
Juan-Manuel Roldan-Fernandez ${ }^{1}\left(\right.$, Javier Serrano-Gonzalez ${ }^{1}\left(\mathbb{D}\right.$, Francisco Gonzalez-Longatt $^{2}(\mathbb{D}$ \\ and Manuel Burgos-Payan $1, * \mathbb{D}$ \\ 1 Department of Electrical Engineering, Universidad de Sevilla, 41004 Sevilla, Spain; \\ jmroldan@us.es (J.-M.R.-F.); javierserrano@us.es (J.S.-G.) \\ 2 Department of Electrical Engineering, Information Technology and Cybernetics, University of South-Eastern \\ Norway, 3918 Porsgrunn, Norway; F.Gonzalez-Longatt@usn.no \\ * Correspondence: mburgos@us.es
}

check for

updates

Citation: Roldan-Fernandez, J.-M.; Serrano-Gonzalez, J.;

Gonzalez-Longatt, F.; Burgos-Payan, M. Impact of Spanish Offshore Wind Generation in the Iberian Electricity Market: Potential Savings and Policy Implications. Energies 2021, 14, 4481. https://doi.org/10.3390/en14154481

Academic Editor: Carlos

Guedes Soares

Received: 19 June 2021

Accepted: 19 July 2021

Published: 24 July 2021

Publisher's Note: MDPI stays neutral with regard to jurisdictional claims in published maps and institutional affiliations.

Copyright: (C) 2021 by the authors. Licensee MDPI, Basel, Switzerland. This article is an open access article distributed under the terms and conditions of the Creative Commons Attribution (CC BY) license (https:/ / creativecommons.org/licenses/by/ $4.0 /)$.

\begin{abstract}
The European Union considers that offshore wind power will play a key role in making the EU the first climate-neutral continent by 2050. Currently, the potential of offshore wind energy is still untapped in Spain. Furthermore, the characteristics of the coastline in Spain require floating technology, making it challenging to install wind farms due to their current high cost. This work seeks to quantify the impact that Spanish offshore wind energy would have on the Iberian electricity market. Several offshore wind scenarios are evaluated by combining available information in relation to areas suitable for installing wind farms and wind resource data. The impact on the day-ahead electricity market has been obtained by reproducing the market, including these new offshore wind generation scenarios. The introduction of this renewable energy results in a market cost reduction in what is known as the merit-order effect. According to our estimates, for each MWh of offshore wind energy introduced in the market, there would be a market cost reduction of $45 €$. These savings can serve as a reference for regulators to adjust their policy framework to boost floating wind offshore generation.
\end{abstract}

Keywords: floating offshore wind farm; day-ahead market; merit-order effect; offshore wind energy

\section{Introduction}

Currently, the European Union seeks to boost the transition to a climate-neutral energy system, by using low-carbon technologies through what is called the Strategic Plan for Energy Technologies or SET-Plan [1]. The European Commission intends to become a world technology leader in floating offshore wind. The European Green Deal [2], approved by the European Union in December 2019, also reinforced this objective and emphasized the importance of offshore renewables, so as to make the EU the first climate-neutral continent by 2050. More precisely, in the case of Spain, the Sectorial Agenda of the Wind Industry [3], in collaboration with the Spanish Ministry of Industry, Trade, and Tourism, identifies offshore wind energy as one of the main future drivers capable of strengthening the Spanish wind industry. In this report, a series of actions are proposed to develop the offshore wind industry. The European wind industry association, Wind Europe, in [4] states that offshore wind energy will help Europe become carbon neutral. This report estimates that $70 \mathrm{GW}$ of offshore wind energy will have been installed in southern Europe by 2050 . A capacity of $13 \mathrm{GW}$ will have been installed in Spain. In the short term, the authors in [5] estimate the installation of $0.25 \mathrm{GW}$ of offshore wind energy by 2022, with a turbine power capacity of 7.8 MW. In addition, by 2019, around 10 floating-type turbines had already been installed in Europe. Regarding the situation in Spain, the authors present the situation in 2015 in [6] as well as the expected growth of offshore wind power facilities. The study analyzes the principal causes of the non-implementation of this technology. The research proposes the development of solutions for floating wind turbines by reducing 
costs, providing a stable regulatory framework and ensuring government approval of complementary measures that promote investment in this field. The Covid-19 Recovery Plan, recently approved by the European Commission to reactivate economies, considers offshore wind power as playing a key role in this regard; therefore, this represents a significant opportunity to encourage investment in this sector. The European Union has agreed to develop offshore wind energy through the Recovery Funds, based on the European Marine Energy Strategy. The commitment of the European Union to promote renewable technologies as part of the scenario to achieve climate neutrality in 2050 has resulted in offshore wind power being considered a fundamental pillar of the energy mix. Specifically, the European Union has set the targets for offshore wind technology at more than 60 GW by 2030 and 300 GW by 2050 [7].

The development of the National Energy and Climate Plans [8], mandatory for all European countries, has indicated that more countries consider offshore wind energy as a key technology in achieving their climate targets. In the case of Spain, offshore wind power has not yet gained sufficient relevance. Contrary to the developments in many European countries in relation to lesser wind conditions, Spain did not include clear objectives with regard to offshore wind power for 2030 (see Table 1). Spain's neighboring countries, such as Portugal or France, whose coastlines have similar characteristics to those of Spain, are already considering floating marine energy as an additional tool to achieve emission reduction targets. Nevertheless, the Spanish Energy and Climate Plan recognizes that marine energy and energy from offshore wind technology in deep waters remain uncompetitive but have great potential. In this respect, the plan suggests that these technologies could be supported with public financing.

Table 1. Target for offshore wind capacity (GW) for Spain, Portugal, and France.

\begin{tabular}{cccc}
\hline Year & $\mathbf{2 0 2 0}$ & $\mathbf{2 0 2 3}$ & $\mathbf{2 0 3 0}$ \\
\hline Spain (onshore + offshore power capacity, GW) & 28 & - & 50.3 \\
Portugal (offshore power capacity, GW) & 0.03 & - & 0.3 \\
France (offshore power capacity, GW) & - & 2.4 & $5.2-6.2$ \\
\hline
\end{tabular}

As previously mentioned, the Spanish Energy and Climate Plan estimates that wind generation capacity will increase by around $22.3 \mathrm{GW}$ between 2020 and 2030, without determining how much power will correspond to offshore wind generation. This equates to a wind power growing ratio of around $2.23 \mathrm{GW} /$ year across the actual decade. Although there are no specific national targets for wind energy, it should be noted that certain regional authorities, in particular the Canary Islands, have set a specific target of 300 MW by 2025 . Likewise, the Spanish wind energy association considers that a national installed quota of between 2000 and 3000 MW by 2030 would be achievable [9].

What is clear is that a percentage of this power should come from offshore technology, since onshore areas/locations with the best wind resources are already being exploited, making it more challenging to find suitable locations for new onshore wind farms. Regarding the potential of Spanish offshore wind energy, the Institute for the Diversification and Saving of Energy in Spain [10] has carried out a detailed study, identifying potential locations for wind farms, considering possible restrictions such as environmental issues, marine traffic, etc. This study concluded that areas with low bathymetry are scarce in the country; therefore, offshore wind generation is primarily associated with floating technology, unlike the enormous developments that have occurred in the North Sea, which are mainly foundation-based technologies. Using floating technology, the extreme depths of the Spanish waters will no longer constitute an obstacle, and Spain will be able to take advantage of the excellent wind resource potential. Moreover, Spain possesses the technological infrastructure to address the demand for future domestic floating technology offshore, since Spain has been exporting components for European offshore wind farms for several years [11]. In 2019, the first offshore wind turbine (gravity-based foundation) was installed on the island of Gran Canaria, with a generation capacity of 5 MW [12]. There are 
several experimental platforms in Spain, as well as multiple prototypes under development by Spanish companies, proving the technological capabilities in offshore wind energy and in floating technology. Some research programs involving the development of floating wind technology, are grouped within the program of Singular Technical Infrastructures [13].

Certain Spanish enterprises/corporations have elaborated on and submitted proposals to the Next Generation EU programme [14], articulated through the Spanish Recovery, Transformation and Resilience Plan of the Ministry of Energy Transition [15], for the commissioning of floating offshore wind facilities on an industrial scale along the coasts of Andalusia, the Canary Islands, and Galicia. For example, Iberdrola [16] plans to allocate more than $€ 1$ billion of investment to commissioning a $300 \mathrm{MW}$ floating offshore wind farm. The company views this project as an opportunity to expand the country's supply chain and convert the Spanish industry as an international benchmark. The development of this project would create around 2800 jobs per year, with the participation of 66 Spanish companies, various technology centers, and numerous small and mid-size enterprises (more than 50). The study [17] estimates that floating offshore wind power alone will create more than 17,000 direct jobs, plus a further 13,000 indirect jobs on the Iberian Peninsula by 2030. In this way, offshore wind energy will contribute very positively to the employment impact foreseen in the Spanish Energy and Climate Plan [8], which estimates a net job creation of between 253,000 and 348,000 by 2030 , as a result of the energy transition process.

Currently, floating offshore wind turbines are less able to compete with other renewable technologies (photovoltaic or onshore wind generation). The levelized cost of energy (LCOE) for floating offshore wind turbines is greater than for fixed offshore wind turbines, since floating technology is more complex. Floating wind farms are located deeper in the ocean to take advantage of stronger winds. The floating structure makes this technology more expensive. In addition, when the distances are greater, there are more cable losses and a higher reactive power compensation (HVAC transmission system). This drastically reduces the active power transmission capacity in the case of lengths greater than $50-70 \mathrm{~km}$ in submarine power system transmission [18]. For longer distances, it is necessary to use an HVDC transmission system. This technology consists of using converter stations, based on power electronics to rectify to direct current. Therefore, although the wind resource is better than onshore resources, offshore wind farms would incur additional costs and higher energy losses. This makes it difficult to compare the LCOE of offshore wind technology with other technologies, such as onshore wind energy or solar power. A recent overview of the current state and future trends of the offshore wind farms along with the technological challenges can be seen in [19]. Geographic information systems-GIS-has also been used for the optimal site selection of floating wind farms [20]. The study considered the about 3.4 million of $\mathrm{km}^{2}$ of the Atlantic Exclusive Economic Zone of Portugal, Spain, and France, where only $0.22 \%$ of that area is able to host floating wind turbines. The authors concluded that the proposed support tool can help decision makers to eliminate unsuitable areas and identify those where sustainability can be maximized. A methodology to calculate the life-cycle cost of floating offshore renewable energy devices (wave and wind) was introduced in [21]. The researchers found that the most important life-cycle cost is the exploitation cost, which is followed by the manufacturing and the installation cost. The LCOE for a floating offshore wind farm was estimated in [22] for different countries. The LCOE varies from 287.8 to $109.3 € / \mathrm{MWh}$. In [23], the authors analyze the feasibility of floating offshore wind farms in Portugal. They found that the LCOE is $289.49 € / \mathrm{MWh}$ for the spar platform, followed by the semisubmersible platform (303.97 €/MWh) and the TLP platform (325.64 $€ / M W h)$. According to the research project [24], the LCOE for $1 \mathrm{GW}$ of floating wind energy in the Celtic Sea by 2035 , would be in the range of $63-90 € / \mathrm{MWh}$. In the case of the west coast of Ireland, the LCOE would vary between 75 and $107 € / \mathrm{MW}$. With regard to these LCOE values, it is clearly difficult to achieve a certain profitability in this type of project, by covering the costs solely with income from the electricity market. A similar conclusion was reached by Castro-Santos et al. in [25]. The authors assessed the economic feasibility of offshore wind farms installed in deep waters considering their 
internal rate of return (IRR), net present value (NPV), and LCOE. They studied the case of the Cantabrian and North-Atlantic coasts of Spain and found that the best value for LCOE was $172.81 € / M W h$ for the semisubmersible platform. The authors also found that present retribution for this type of technology in Spain is not enough to support the great investment necessary in this type of offshore wind farm, since they estimated that the necessary compensation for this type of installation to be profitable should be about $200 € / M W h$.

In 2020, the Real Decree 960/2020 [26] established a new remuneration system for renewable energy sources (RES), based on a tendering system using contracts-for-difference (CfDs). The main objective of a tender, as a competitive bidding procedure, is to determine cost-efficient support levels for RES technologies. In relation to the CfDs, wind farms pay back when the market price exceeds the auction price. Governments only pay out when the market price is lower than the auction price. This regulatory system considers a minimum and maximum bid level (price caps). On one hand, bids above the maximum price are rejected (to incentivize bids that take into account its costs). On the other hand, bids below the minimum are also rejected. Admitted bids between the price caps will be arranged in ascending order, until the tendered volume limit is reached. The first tender was submitted in January 2021 for a generation capacity of 3 GW [27]; there was no capacity reserve for offshore wind generation. The tendered volume was distributed for a generation capacity of $1 \mathrm{GW}$ for solar photovoltaic generation (PV), $1 \mathrm{GW}$ for onshore wind generation, and $1 \mathrm{GW}$ without any technology restrictions. The PV generation was finally awarded with two-thirds of the tendered volume. There were no bids from offshore agents, and the auction resulted in the lowest ever prices for onshore wind energy in Europe. The onshore wind bids ranged from 20 to $28.89 € / \mathrm{MWh}$. The maximum price cap was not published, since the regulation establishes that the maximum price cap might be confidential and might only be known by the agents participating in the tendering process. Technology neutral auctions would put offshore wind projects at a disadvantage when forced to compete on price with onshore wind or solar projects. In the event that the government organizes a specific auction for offshore wind generation, the government should consider the characteristics of this technology and its state of maturity. Otherwise, the auction may not be successful. The aim of this work is to estimate the economic impact of this technology on the day-ahead electricity market that could be used by the government or policy makers to adjust or establish the remuneration regime for this technology, either within the current regulatory framework or another framework. Policy makers have to find a balance between the benefits provided by the technology they are trying to promote and the cost of that generation. The integration of renewables creates economic benefits for consumers when they participate in the day-ahead electricity market. This effect, described in [28-31], is known as the merit-order effect, and it constitutes a decrease in energy prices when renewables offer their energy at a very low price in a day-ahead electricity market. This work seeks to estimate the impact that offshore energy would have on the day-ahead Iberian electricity market. The potential savings can serve as the basis for the Spanish government or policy makers to promote the development of floating offshore wind energy as another instrument to achieve decarbonization and meet EU targets. The purpose of this study is twofold: firstly, we estimate the floating offshore wind resources in the most likely location and their impact on the daily electricity market, obtaining the new clearing prices. Secondly, for different scenarios relating to floating offshore wind energy penetration, we quantify the new market cost, obtaining the cost reduction per MWh of floating offshore wind energy. The estimate of the merit-order effect of the offshore technology could be used to modulate auctions (set maximum prices) or design subsidies or premiums accordingly.

The document's structure is as follows: Section 2 analyzes the wind resources and describes the method to reproduce the day-ahead electricity market. Section 3 details how the market responds to this new generation and discusses the main findings. Section 4 concludes. 


\section{Materials and Methods}

Firstly, to determine how floating offshore wind generation would affect the market, it is necessary to estimate hourly wind energy production. To evaluate the wind resource, we assume that wind farms will be installed in those areas where the wind resource is abundant and with few environmental or maritime constraints. Based on these assumptions, four locations have been chosen for offshore wind farms: the North Atlantic zone (north and west of Galicia), the South Atlantic zone (southwest of Andalusia), and the North Mediterranean zone (Catalonia). Figure 1 shows the locations of the wind farms. The maps also represent the mean wind speed. The mean wind speed estimate was obtained from the Global Wind Atlas [32]. This application uses large-scale wind climate data and extrapolates it to micro-scale wind data (by means of a downscaling process). The mean wind speeds shown in the figure correspond to the period 2008-2017, with a calculation node spacing of $250 \mathrm{~m}$.
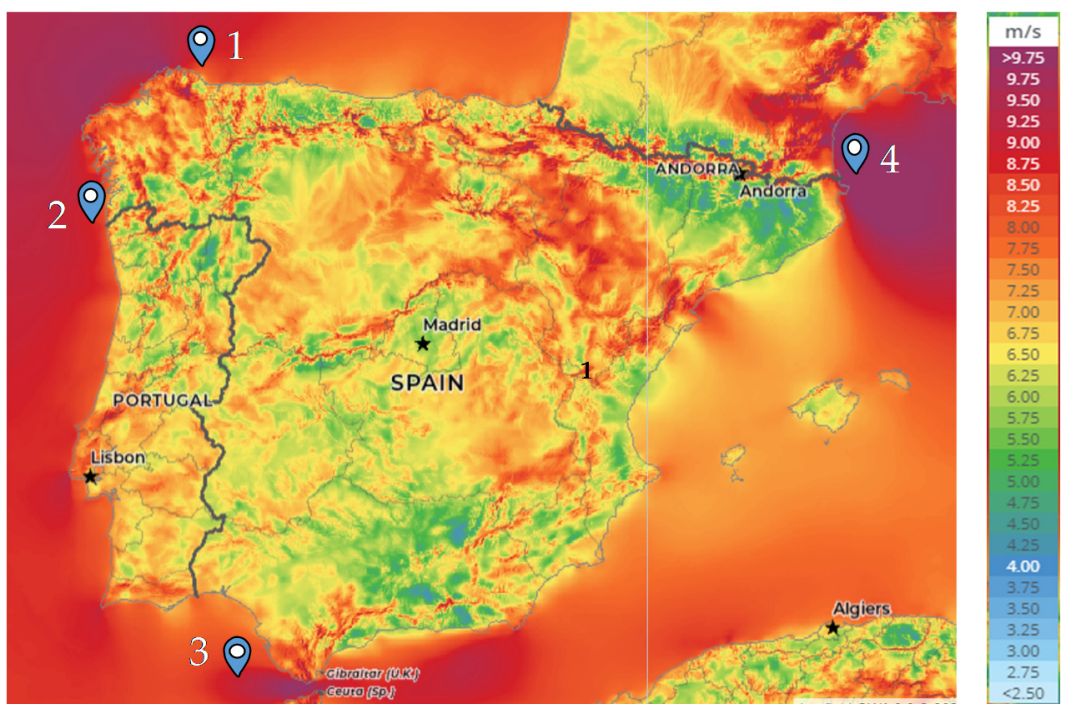

Figure 1. Offshore wind farm locations and mean wind speed [32].

The wind resource characteristics and restrictions in each area are detailed in the next section. Different levels of wind power capacity are assumed for these locations, and the effect on the daily electricity market is evaluated using the hourly information retrieved from the Iberian market operator (OMIE) [33].

\subsection{Offshore Wind Locations in Spain and Wind Resource Analysis}

In 2011, the Spanish Government's Institute for the Diversification and Saving of Energy (IDAE) published a report analyzing the country's wind resources [10]. The atlas addressed the offshore wind resources, based on a previous assessment of the suitable locations carried out by the Ministry of Agriculture and the Ministry of Industry, which is called the Strategic Environmental Study of the Spanish Coast for offshore wind farms [34]. Of the entire coastline, only $8.15 \%$ of this has a depth shallower than $50 \mathrm{~m}$. The atlas also provides information on the suitability of the site to host offshore wind farms, subject to environmental and maritime restrictions (Tables 2 and 3). The country's coast is divided into several areas, and these are characterized as follows:

- Suitable areas, which meet all the necessary characteristics for the installation of offshore wind farms, without prejudicing the environmental impact.

- Suitable areas with environmental restrictions. These are areas where the development of offshore wind farms requires a detailed environmental assessment.

- Excluded areas, where the installation of offshore wind farms is not permitted for environmental reasons or other marine uses. 
Table 2. Breakdown of marine surfaces for offshore wind farms [10].

\begin{tabular}{ccc}
\hline Areas & Surface $\left.\mathbf{( k m}^{\mathbf{2}}\right)$ & Surface $\mathbf{( \% )}$ \\
\hline Suitable & 84,666 & 36.8 \\
Suitable areas with environmental restrictions & 89,759 & 39 \\
Excluded areas & 55,889 & 24.3 \\
Total & 230,314 & 100 \\
\hline
\end{tabular}

Table 3. Annual average wind speeds in suitable locations and in areas with constraints for offshore wind farms [10].

\begin{tabular}{ccc}
\hline Wind Speed $\mathbf{( m} / \mathbf{s})$ at $\mathbf{8 0} \mathbf{~ m}$ & Surface $\left.\mathbf{( k m}^{\mathbf{2}}\right)$ & Surface $\mathbf{( \% )}$ \\
\hline $7.5-8.0$ & 28,169 & 16.15 \\
$8.0-8.5$ & 13,652 & 7.83 \\
$8.5-9.0$ & 10,517 & 6.03 \\
$9.0-9.5$ & 10,264 & 5.88 \\
$9.5-10.0$ & 6617 & 3.79 \\
$>10.0$ & 2331 & 1.34 \\
Total & 71,550 & 41.00 \\
\hline
\end{tabular}

The surface with a sufficient wind speed (greater than $7.5 \mathrm{~m} / \mathrm{s}$ at $80 \mathrm{~m}$ ) can be seen in Table $3\left(71,550 \mathrm{~km}^{2}, 41 \%\right.$ of the surface not excluded).

Figures 2 and 3 gather information regarding the suitability of the areas to host wind farms and the characteristics of the wind speed, provided by the Strategic Environmental Study of the Spanish Coast [34] and the Global Wind Atlas [32]. The four locations were chosen to locate floating offshore wind farms, which correspond to areas where the wind resource is abundant. The figure also highlights large areas with environmental protection or with certain types of restrictions for the installation of offshore wind farms.

The effect on the market will be more significant when more renewable energy solutions are available. Therefore, it is necessary to estimate the wind resources in the locations suitable for the installation of wind farms. As can be seen in Figures 2 and 3, the wind resource at each location has different characteristics in terms of the predominant wind direction and the hours in the day when the highest mean wind speed occurs. The temporal plots shown in Figures 2 and 3 have a variable called the wind speed index (the hourly mean wind speed divided by the 10-year mean wind speed at that point). The wind speed index provides information on the mean wind speed during a specific period by comparison with the normal wind speed. A wind speed index larger/smaller than one means that the wind speed in the analyzed period has been on average greater/less than normal. Normal is defined as the mean wind speed over a long period (from 2008 to 2017).

In Figure 2, for location 1 (north coast of Galicia), the most frequent wind direction is from the east. The wind reaches a higher speed during the day from 12 to 19. Regarding location 2 (west coast of Galicia), the wind blows more frequently from the north, and the wind speed is higher from 14:00 to 00:00.

In Figure 3, with regard to location 3 (west coast of Andalusia), the wind blows more frequently from the east. Here, the higher wind speed is evident during the night from 22:00 to 03:00. Regarding location 4 (north coast of Catalonia), the wind comes mainly from the northwest, and the wind speed is higher from 18:00 to 00:00. In the case of locations 2,3 , and 4 , there are more wind resources during the afternoon or evening. The Spanish Energy and Climate Plan establishes that photovoltaic solar energy should be increased by $30 \mathrm{GW}$ by 2030 . Therefore, there would be a certain complementarity between the two technologies. 

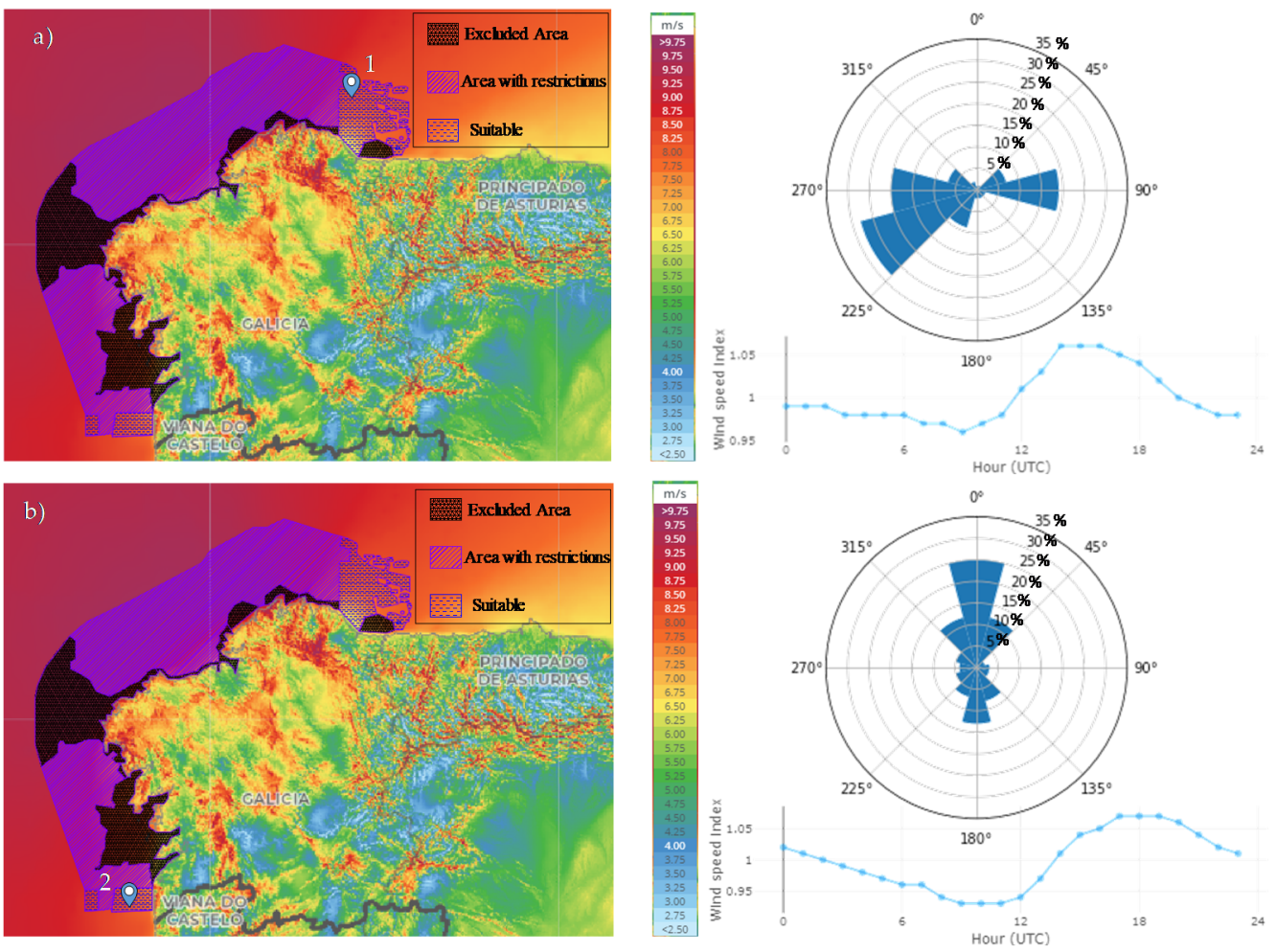

Figure 2. (a) North coast of Galicia and (b) west coast of Galicia. Excluded, conditioned, and suitable areas for offshore wind generation (northwest of Spain). Mean wind speed at $100 \mathrm{~m}$, frequency rose, and hourly wind speed index. Adapted from [32,34].
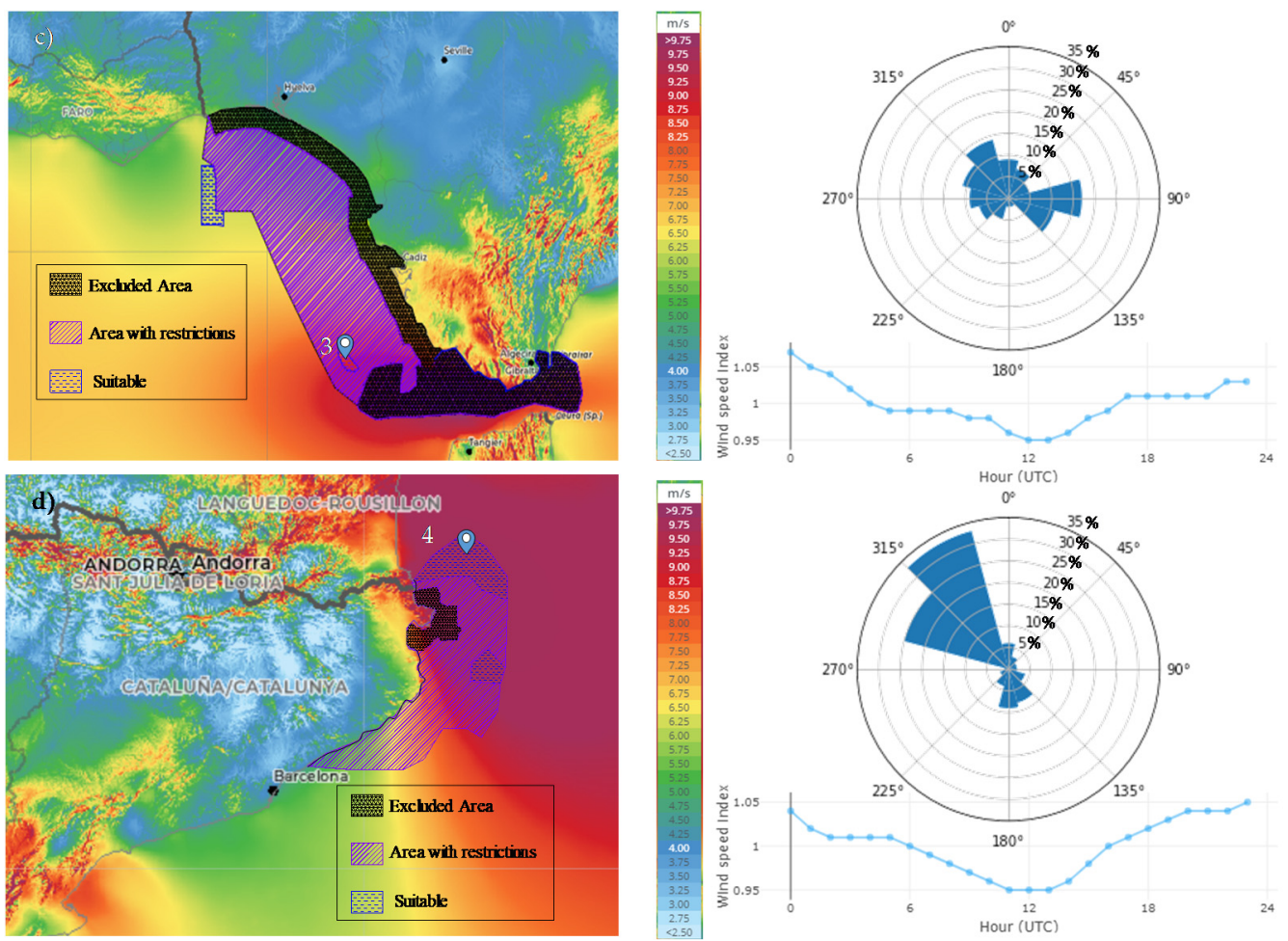

Figure 3. (c) West coast of Andalusia and (d) north coast of Catalonia. Excluded, conditioned, and suitable areas for offshore wind generation (southwest and northeast of Spain). Mean wind speed at $100 \mathrm{~m}$, frequency rose, and hourly wind speed index. Adapted from [32,34]. 
In addition to the information provided by the Global Wind Atlas, hourly wind data are necessary, as wholesale energy prices and traded energies are determined hourly. For this purpose, we use the hourly wind data estimated from marine buoys and measurement towers located along the entire coast of the country (Spanish ports, [35]). Figure 4 summarizes the procedure followed in this work. Firstly, once the location of the four wind power plants has been set, the local wind speed time series from the Spanish ports [35] and the considered wind turbine power curve, $P_{T}(v)$, have been used to estimate the hourly energy production, $E_{A, h}$, corresponding to the array, $A$, and the hour, $h$, as follows:

$$
E_{A, h}=N_{T} \cdot\left(1-p_{L}\right) \cdot E_{A, T, h}=N_{T} \cdot\left(1-p_{L}\right) \cdot \int_{t=h}^{t=h+1} P_{T}\left(v_{A}(t)\right) \cdot d t
$$
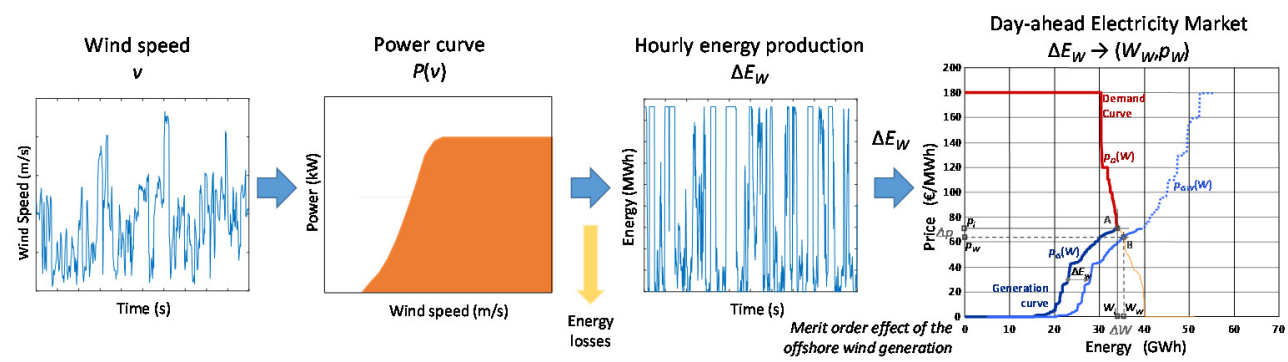

Figure 4. Graphic representation of the procedure for estimating the impact of the offshore wind generation on the day-ahead electricity market.

In this expression, $N_{T}$ is the considered number of turbines of each array, $p_{L}$ represents the relative total losses of the array (wake losses and electrical loses in the inner electricity infrastructure), and $E_{T, h}$ is the hourly energy produced by one turbine per hour, $h$.

Subsequently, the aggregate hourly quantity of wind energy at the national level, $\Delta E_{W, h}$, that is integrated into the market is estimated as:

$$
\Delta E_{W, h}=\sum_{A=1}^{N_{A}} E_{A, h}
$$

where $N_{A}$ represents the considered number of arrays.

\subsection{Offshore Wind Energy Integration in the Iberian Market}

The basic information used in this work to determine the effects of the integration of the offshore wind energy in the Iberian day-ahead market includes the hourly curves of generation and demand, which are ranked by the price for the year 2019 (365 daily markets, with thousands of production and demand bids in each daily market, resulting in 8760 hourly demand and generation curves, each with a thousand bids). These data can be obtained from the Iberian market operator, OMIE [33]. A large number of daily markets (numerous production and demand bids) renders it convenient to consider a certain level of simplification, so as to reproduce the market operation. The Iberian market is driven by a complex process of optimization of economic welfare in order to determine the market-clearing point (clearing price and traded energy).

To model the operation of the day-ahead electricity market, using such broad scenarios as those considered in this work (one whole year), the existing literature has used different approaches, such as the linearization of the market around the clearing point $[29,36,37]$. Research based on a market model, using the detailed composition of the generation and demand curves, can be found in [30,38-40]. The latter methodology has been adopted in this work, which requires very detailed information of the composition of generation and demand curves. Our approach is based on a ceteris paribus assumption, keeping constant all factors except the generation curve, which is modified to integrate the offshore wind 
production bids. Subsequently, the new hourly prices of traded energy and clearing are recalculated for each hour of the year.

For every potential offshore scenario, a new hourly merit-order generation curve is produced by first adding the hourly energy bids of offshore generators and re-elaborating the corresponding hourly merit-order generation curves. Renewable generators usually offer their energy at (zero or) at a very low price (closely related to their maintenance costs and generally well below the clearing price) in order to guarantee their participation when the energy resource is available, and their fuel costs are zero.

Once the generation curve was modified, including the offshore generation bids, the new clearing point $\left(W_{W}, p_{W}\right)$ is determined as the intersection of the new supply $\left(p_{G W}=p_{G W}(W)\right)$ and the original demand curves $\left(p_{D}=p_{D}(W)\right)$. For example, Figure 5 shows the quantity of offshore wind generation, $\Delta E_{W}$, at zero cost and the original hourly merit-order generation $\left(p_{G}=p_{G}(W)\right)$ and demand $\left(p_{D}=p_{D}(W)\right)$ curves retrieved from the OMIE. Since renewable generators offer their energy at zero price, the original bids corresponding to the renewable generators can be found in the initial flat region (first steps) of the aggregated generation curve. The original renewable generation bids are now increased until the targeted amount $\left(\Delta E_{W}\right)$ is reached. The new aggregated generation curve, $p_{G W}=p_{G W}(W)$, essentially results in a right-shifting of the initially cleared supply curve, by an amount equal to $\Delta E_{W}$. Finally, the new clearing point (B in Figure 5) can be determined as the crossing point of the new right-shifted generation curve, $p_{G W}=p_{G W}(W)$, with the original demand curve, $p_{D}=p_{D}(W)$. It is important to emphasize that this approximate clearing method retains the stepped characteristic of the curves.

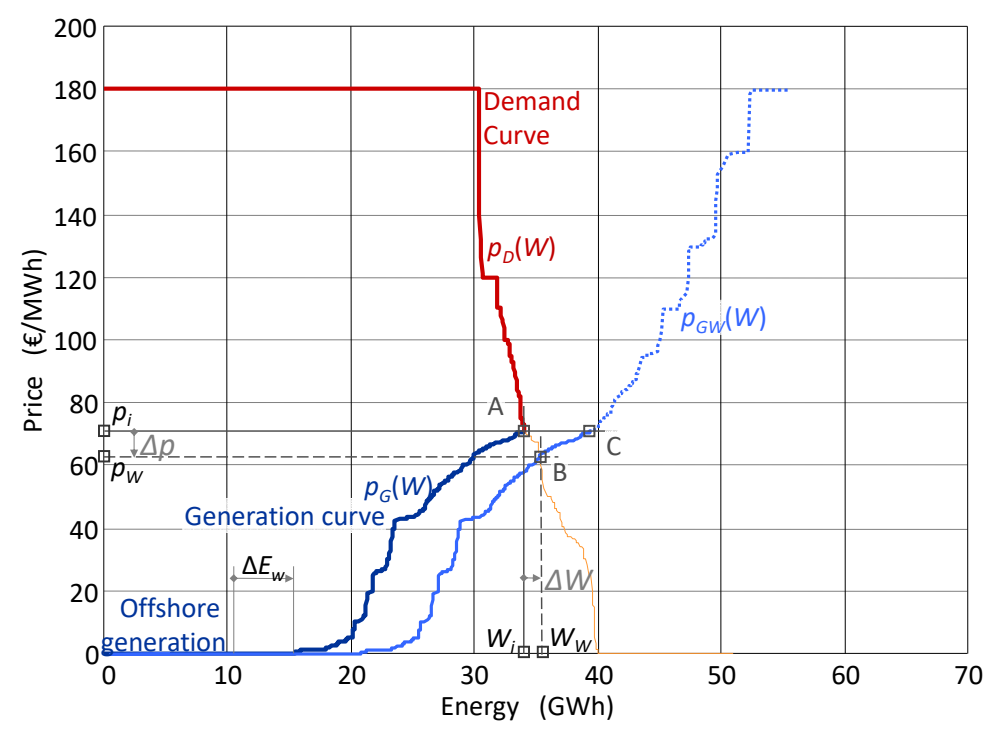

Figure 5. Hourly aggregated generation, $p_{G}=p_{G}(W)$, and demand, $p_{D}=p_{D}(W)$, curves and elaboration of the new right-shifted generation curve, $p_{G W}=p_{G W}(W)$, integrating an amount of new offshore wind production, $\Delta E_{W}$ (selling bids at zero price).

Figure 5 shows how the integration of the offshore generation bids leads to an appreciable reduction in the clearing price and a slight increase in the energy traded in the market (rebound effect). As a result, the cost of the energy traded in the market (the product of the energy by the price, $C_{W}=W_{W} \cdot p_{W}<C_{i}=W_{i} \cdot p_{i}$ ) is also reduced. This is the well-known merit-order effect of renewables in the market [28].

Although a precise evaluation of the avoided $C \mathrm{O}_{2-e q}$ emissions, $\Delta V_{\mathrm{CO}_{2-e q}}$, requires the identification of the technology and the amount of energy produced by every generator unit hourly, dispatched by the market operator over a particular year, a simplified evaluation can be conducted, based on the average emissions factor, $F_{\mathrm{CO}_{2-e q}}$ [41] as follows:

$$
\Delta V_{\mathrm{CO}_{2-e q}}=\left(\Delta E_{W}-\Delta W\left(\Delta E_{W}\right)\right) \cdot F_{C_{2-e q}} .
$$




\section{Results and Discussion}

Firstly, this section presents the details of the considered offshore wind scenarios. Next, the impact of offshore wind generation on the market is presented. A short discussion on the method, data, and results closes the section.

\subsection{Offshore Scenarios}

Each of the three scenarios considers four different locations for the arrays, as shown in Figure 2. In all the cases, the offshore arrays are integrated by wind turbines with $8 \mathrm{MW}$ of rated power capacity; the data sheet and power-speed curve $\left(P_{T}(v)\right)$ can be found in [42]. This rated power has been chosen based on [43], which states that three quarters of the current offshore wind farms use turbines of $7 \mathrm{MW}$ and above (the average turbine rated power was 7.8 MW in 2019).

As mentioned, three offshore wind scenarios have been considered.

- Scenario $1(4 \cdot 30=120$ turbines): total offshore wind power rated capacity $4 \times 240=$ $960 \mathrm{MW}$

o Arrays. Offshore wind power rated capacity per array $240 \mathrm{MW}$ (30 turbines/array)

- Scenario $2(4 \cdot 60=240$ turbines): total offshore wind power rated capacity $4 \times 480=$ 1920 MW

o Arrays. Offshore wind power rated capacity per array 480 MW (60 turbines/array)

- Scenario $3(4.90=360$ turbines): total offshore wind power rated capacity $4 \times 720=$ $2880 \mathrm{MW}$

o Arrays. Offshore wind power rated capacity per array 720 MW (30 turbines/array)

The capacities of the considered scenarios have been chosen, based on the capacity values contained in the last auction $(3 \mathrm{GW})$ and the annual growth of wind capacity, foreseen in the National Plan (2.23 GW/year). Accordingly, the rated capacities of the considered scenario could be achieved in the short term, since they constitute a small fraction of the $13 \mathrm{GW}$ foreseen by Wind Europe [4].

The net hourly energy production of each array offered to the market operator is determined considering $10 \%$ of total power losses. That is, $p_{L}=0.1$ p.u. (wake losses and electrical loses within the inner electricity infrastructure of the array). For each hour of the year, the wind farm would offer this energy in the day-ahead electricity market, modifying the aggregated generation curve, as explained in Section 2.2. Secondly, the hourly energy production is obtained using the wind turbine power curve.

\subsection{Integration of the Offshore Generation in the Iberian Market}

The response of the electricity market to the integration of offshore wind production is rather complex. It depends on multiple factors, such as the composition of the hourly demand and generation curves (average slopes of the generation and demand curves) and the hourly distribution of offshore wind generation. Figure 6a illustrates the behavior of the aggregate wind generation for the four considered sites. This figure represents the aggregate production of the four sites in the $4 \times 480 \mathrm{MW}$ scenario of offshore power capacity (Scenario 1). As can be seen, the aggregate production for the year 2019 indicates a higher level of generation during January and May. In general terms, wind generation is lower during the middle of the day. This suggests that offshore wind resources would complement the photovoltaic generation, which has a higher production during the middle of the day. 

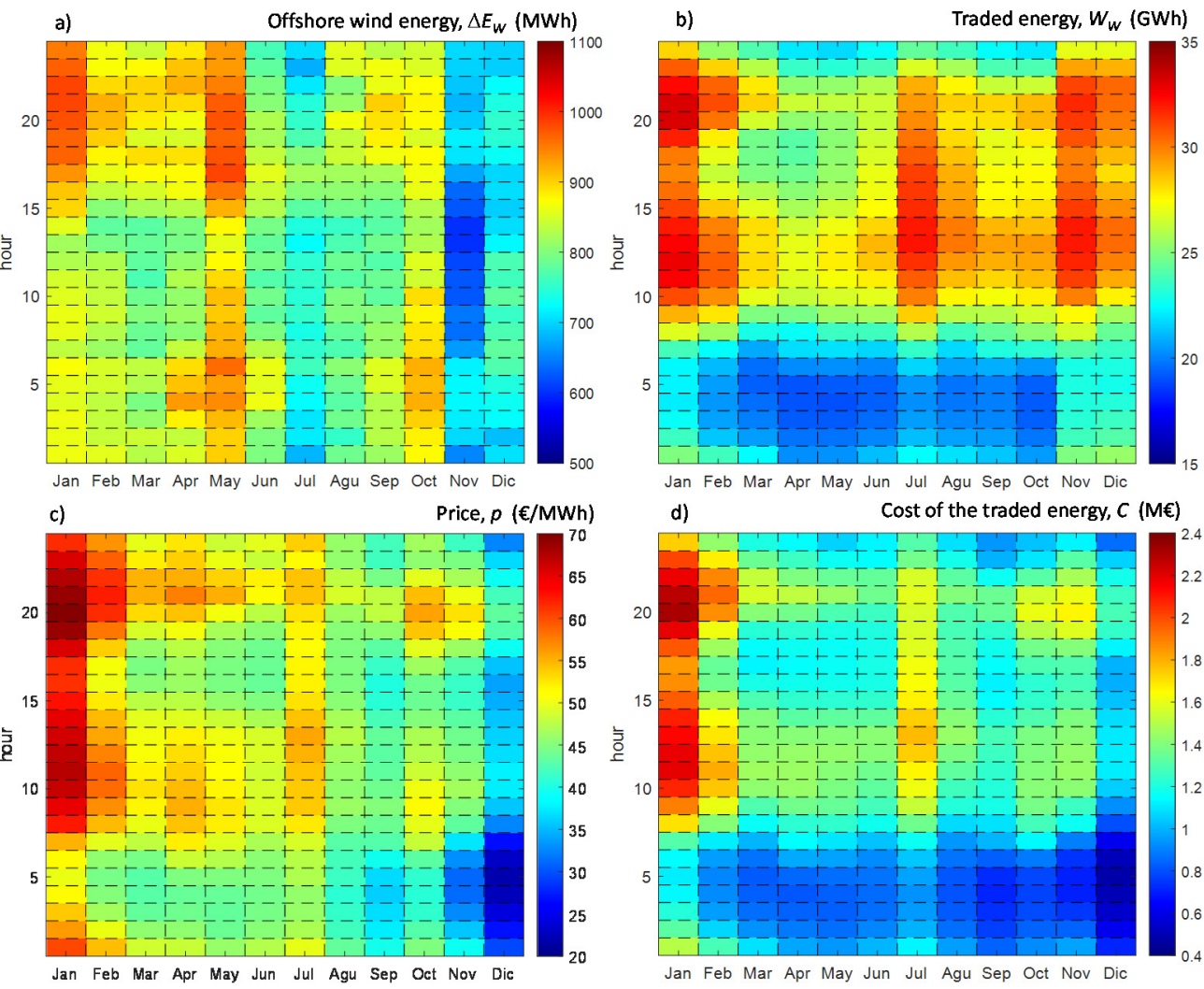

Jan Feb Mar Apr May Jun Jul Agu Sep Oct Nov Dic

$$
\text { d) }
$$

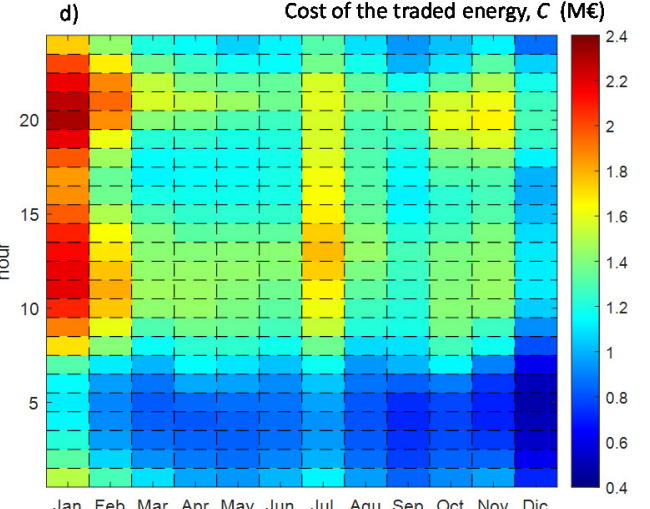

Jan Feb Mar Apr May Jun Jul Agu Sep Oct Nov Dic

Figure 6. Hourly mean values per month for (a) the offshore wind energy production for Scenario 2. $4 \times 480 \mathrm{MW}$, (b) the traded energy, (c) the clearing price, and (d) the cost of the traded energy in the market.

Regarding the Iberian market, the general rule of thumb is to expect high energy prices and costs when demand is high, but the technology composition of the generation also counts. For example, January, February, and July follow this trend (Figure $6 \mathrm{~b}, \mathrm{c}$ ). However, November and December, which have one of the highest levels of traded energy, have low energy prices. This reason for this is that during these months, there is significant hydro production, reducing energy prices. As a consequence, the energy costs reached the maximum in January (Figure 6d).

As was explained in Section 2.2, offshore wind production has the capacity to impose downward pressure on the market prices while producing a slight growth in energy consumption. As a result of these opposed variations, the total cost of the energy traded in the market is also reduced. Conversely, lower energy prices lead to a rebound effect that creates a greater volume of traded energy. This is motivated by the fact that offshore wind generators, as renewable generators, offer their energy at zero or at a very low price, to ensure they are dispatched (cleared) by the market operator, when the renewable energy resource (wind) is available.

By re-elaborating the task of the market operator, as stated in Section 2.2, the new hourly clearing points are determined. That is, the new values of the hourly clearing prices and traded energies (and total costs of the traded energy in the market) are calculated for a whole year ( 8760 hourly market slots). Figures 7 and 8 summarize the main results for Scenario $2(4 \times 480 \mathrm{MW})$, while Table 4 summarizes the results for each of the three considered scenarios. 


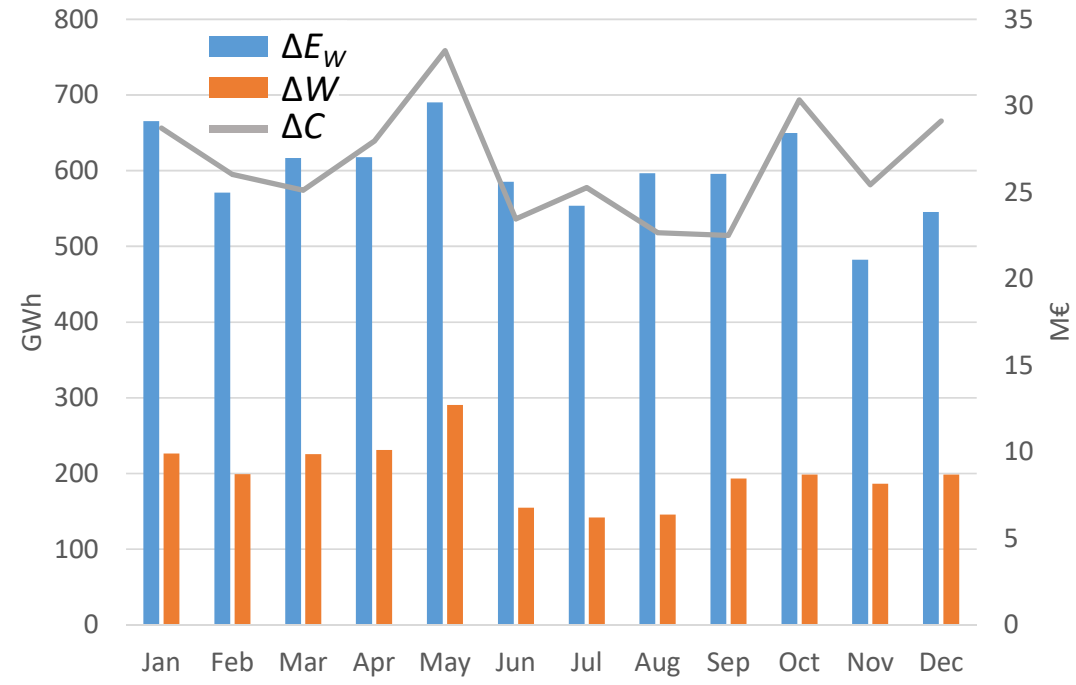

Figure 7. Accumulated values per month for Scenario $2,4 \times 480 \mathrm{MW}$ : the wind offshore production integrated in the market $\left(\Delta E_{W}\right)$, the increase in traded energy $(\Delta W)$, and the decrease in the energy $\operatorname{cost}(\Delta C)$.
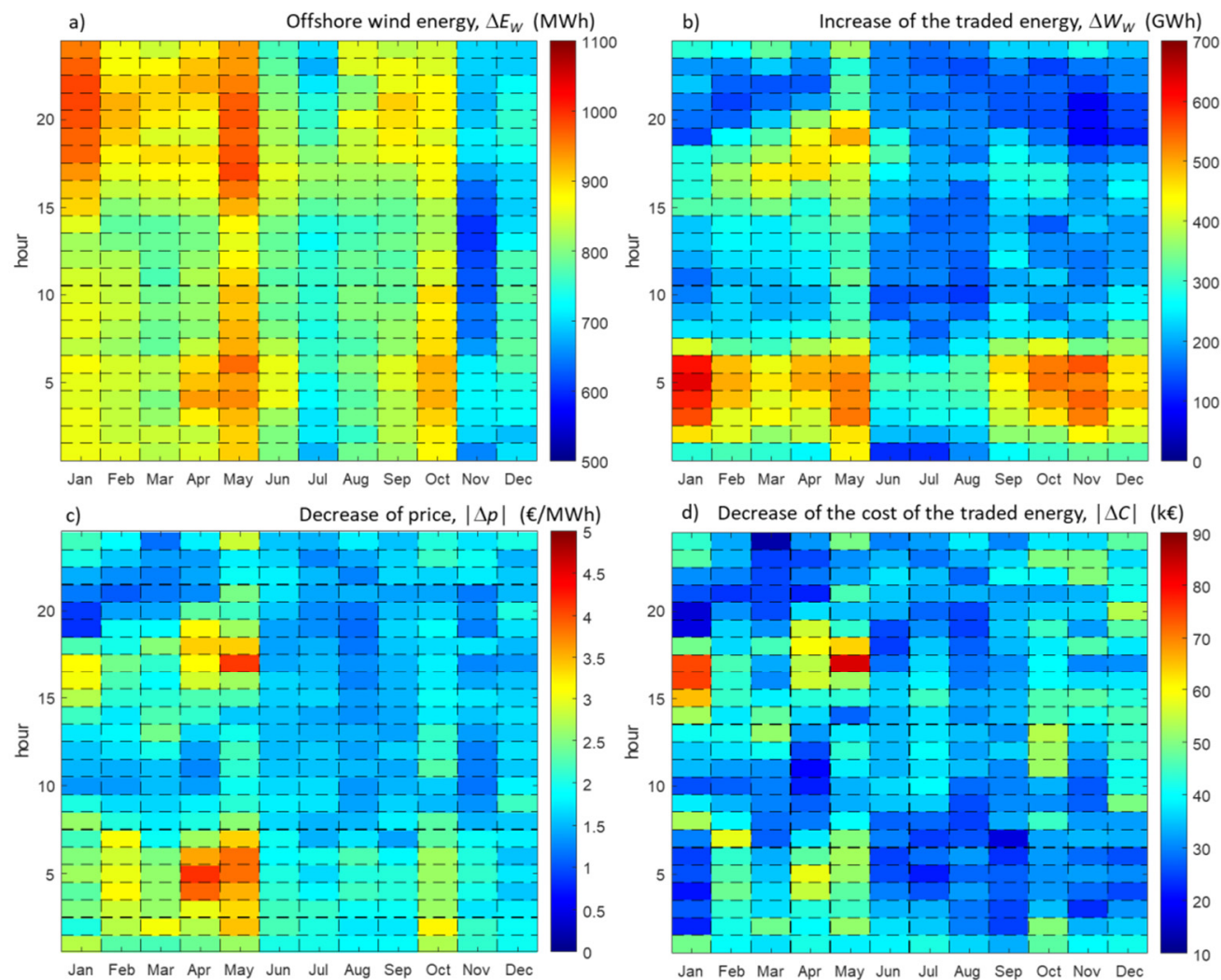

Figure 8. Hourly mean values per month for Scenario 2, $4 \times 480 \mathrm{MW}$ : (a) the offshore wind production integrated in the market $\left(\Delta E_{W}\right),(\mathbf{b})$ the increase in traded energy $(\Delta W)$, (c) the decrease in clearing prices $(\Delta p)$, and $(\mathbf{d})$ the decrease in energy costs $(\Delta C)$. 
Table 4. Variation of the traded energy, the average hourly price, and the annual cost of the traded energy in the Iberian day-ahead electricity market considering offshore scenarios.

\begin{tabular}{|c|c|c|c|c|}
\hline Year 2019 & & $\begin{array}{l}\text { Traded Energy } \\
W=227.2 \mathrm{TWh}\end{array}$ & $\begin{array}{c}\text { Price } \\
p=47.68 € / \mathrm{MWh}\end{array}$ & $\begin{array}{c}\text { Cost } \\
C=10,976.49 \mathrm{M€}\end{array}$ \\
\hline Variations & Units & $\begin{array}{c}\text { Scenario } 1(4 \times 240 \mathrm{MW}) \\
\Delta E_{W}=3585 \mathrm{MWh}\end{array}$ & $\begin{array}{c}\text { Scenario2 }(4 \times 480 \mathrm{MW}) \\
\Delta E_{W}=7170 \mathrm{MWh}\end{array}$ & $\begin{array}{c}\text { Scenario } 3(4 \times 720 \mathrm{MW}) \\
\Delta E_{W}=10,755 \mathrm{MWh}\end{array}$ \\
\hline$\Delta W\left(\Delta E_{W}\right)$ & GWh & 1155.82 & 2390.98 & 3699.43 \\
\hline$\Delta p\left(\Delta E_{W}\right)$ & $€ / \mathrm{MWh}$ & -0.97 & -1.93 & -2.90 \\
\hline$\Delta C\left(\Delta E_{W}\right)$ & M€ & -160.89 & -319.83 & -481.11 \\
\hline$\Delta W\left(\Delta E_{W}\right) / \Delta E_{W}$ & - & 0.3224 & 0.3335 & 0.3440 \\
\hline$\Delta p\left(\Delta E_{W}\right) / \Delta E_{W}$ & $€ / \mathrm{GWh}^{2}$ & -0.270 & -0.269 & -0.270 \\
\hline$\Delta C\left(\Delta E_{W}\right) / \Delta E_{W}$ & $€ / \mathrm{MWh}$ & -44.88 & -44.61 & -44.73 \\
\hline$\Delta V_{\mathrm{CO}_{2-e q}}$ & $t C \mathrm{O}_{2-e q}$ & 466.40 & 917.57 & 1354.67 \\
\hline
\end{tabular}

Figure 7 shows the aggregated results of wind offshore power capacity on a monthly basis, which were calculated for Scenario 1, $4 \times 480 \mathrm{MW}$. The monthly traded energy varies between 554 GWh in July and 690 GWh in May. Despite the increase in traded energy, the reduction in the price is significant enough to produce a clear net decrease in the total cost of the energy traded in the market. As shown in the figure, the increase in traded energy (rebound effect) varies from $24 \%$ in August to $42 \%$ in May, constituting $30 \%$ to $40 \%$ of the total amount of offshore wind energy integrated in the market. The market cost reduction fluctuates between $23 \mathrm{M} €$ in September and $33 \mathrm{M} €$ in May.

Figure 8 shows the results in more detail, using the hourly mean values per month. The most significant price and cost reductions occur in January and May during night hours (between 01:00 and 08:00) and at times between 15:00 and 20:00. The period between June and September has a lower impact on the market.

Table 4 summarizes the main results corresponding to each of the three considered scenarios. In general terms, the following behavior of the market can be observed.

- Traded energy. There is a slight increase in the traded energy. This effect is called the rebound effect. A lower energy price encourages certain consumers to purchase more energy. The traded energy grows by around $33 \%$ in relation to the total amount of wind energy $\left(\Delta E_{W}\right)$. This growth is due to the fact that the demand curve is not entirely vertical around the original market clearing point. If the demand curve was completely vertical around the equilibrium point, there would be no increase in the traded energy. In other words, the rebound effect is due to certain consumers (often large industrial consumers) being willing to buy more energy when the clearing price is low enough.

- Clearing price. There is a reduction in the hourly mean price of around $0.27 €$ per GWh of wind offshore production for all scenarios. As shown below, this effect is more significant than the increase in traded energy, and therefore, price variation produces a corresponding reduction in the total cost of energy traded in the market.

- Cost of the traded energy. As mentioned above, there is a generalized reduction in the cost of traded energy. This cost decreases by around $44.74 €$ for each MWh of floating offshore wind energy.

The avoided volume of $\mathrm{CO}_{2-e q}$ emissions, $\Delta V_{\mathrm{CO}_{2-e q}}$, has been estimated by means of (3) using the average emissions factor, corresponding to the Iberian System in 2029, $F_{\mathrm{CO}_{2-e q}}=192 t \mathrm{CO}_{2-e q} / \mathrm{GWh}$ [41]. For Scenario 2, every GWh of offshore wind production integrated in the market reduces the volume of $\mathrm{CO}_{2}$ equivalent emissions in $128 \mathrm{tCO}$-eq $\left(\Delta V_{C_{2-e q}} / \Delta E_{W}=128 t C O_{2-e q} / \mathrm{GWh}\right)$.

\subsection{Discussion}

As stated in Section 2.1, the methodology to estimate the gross production of every array is estimated based on the local wind speed time series and the power curve, $P_{T}(v)$, 
of the selected wind turbine and the number of turbines, $N_{T}$. Then, after subtracting the fraction of total losses of the array (wake losses and electrical loses in the inner electricity infrastructure), $p_{L}$, results in the net production. Although the value of the relative total losses actually depends on the wind direction (wind rose), here, a global constant value, $p_{L}=0.1$ p.u., has been considered. This simplification has been adopted for two main reasons. The first is that a detailed calculation of the wake effect for each wind direction of each wind rose, would have required some optimization of every array, which is a really difficult task that is out of the scope of this work (even the selection of the type of wind turbine should have been optimized in line with the characteristics of the wind condition of each location). The second is that the hourly production integrated into the market corresponds to the sum of the four marine facilities. It is to be expected that there will be some compensation for error (spatial smoothing effect).

As explained in Section 2.2, the integration of an amount of offshore wind generation at zero or at a very low price (well below the actual clearing) leads to a right-shifting (from the bid price) of the generation curve. This right-shift of the generation curve pushes the new market clearing point down and slightly to the right, as illustrated in Figure 5 . The reduction of the new clearing price is clearly related to the fact that in the new dispatch, an expensive bid of generators, placed between points B and C in Figure 5 (marginal units of the initial situation) are now replaced by chipper wind offshore production, $\Delta E_{W}$. Figure 5 also shows the purchase bids located between A and B. In the initial situation, these bids are not dispatched by the market operator, since their price is lower than the initial price of the market. Nevertheless, after the integration of offshore wind production, purchase bids between A and B will result, dispatched by the market operator, since the new clearing price is now lower than their bid prices.

On average, regarding the considered scenarios, Table 4 shows that the rebound effect $\left(\Delta W\left(\Delta E_{W}\right) / \Delta E_{W}\right)$ grows almost linearly from $32.24 \%$ in Scenario 1 to $34.40 \%$ in Scenario 3. That rebound effect is only a small fraction of the initial traded energy $\left(\Delta W\left(\Delta E_{W}\right) / E_{i}\right)$, ranging between $0.51 \%$ and $1.63 \%$.

The integration of offshore wind energy leads to a rent transfer between market agents, from producers (generators) to consumers. In general terms, generator units reduce their income, since they now sell almost the same amount of energy, but at a lower price. The income reduction is especially significant for certain conventional generators, those located between points $B$ and $C$ in Figure 5, since they are removed from the initial dispatch list (no income at all). On the contrary, consumers profit from the reduction of the cost of the energy they buy in the market.

The Spanish Energy and Climate Plan considers that in addition to wind energy, photovoltaics will play an important role in reaching the emission targets. An electricity system in which renewables make an increasing contribution is a challenge, due to the variability of renewable resources. In this work, offshore wind farms are sited in locations with abundant resources and without environmental constraints. However, it would be interesting to study how to combine offshore wind energy with photovoltaic production, in order to smooth the output. Several studies show a negative correlation between solar and wind output, especially on a monthly/seasonal scale [44]. The wind resources at the locations shown in this study were generally more abundant at times of lower solar production. The variability of energy production could be decreased by the optimal siting of wind production locations. It is also important to remember that the range of possible locations is wide, as areas with restrictions could host wind farms, should detailed environmental impact studies so advise.

\section{Conclusions}

Offshore wind energy already appears in the national energy plans of various European countries, as a key element in controlling $\mathrm{CO}_{2}$ emissions. According to the objectives of the Spanish Energy and Climate Plan, as well as the position of the wind industry, it seems possible to achieve an installed capacity in Spain of up to 3000 MW by 2030, consist- 
ing of projects that would be executed mainly during the period 2025-2030, indicating an installation quota of around $600 \mathrm{MW}$ per year. Nevertheless, for those countries where the sea depth is high, it is necessary to resort to expensive solutions with floating technologies used currently. To try to attract investment in these key sectors and promote their development, it is necessary that the current regulatory framework allows a reasonable return for investors. There are numerous studies that analyze the LCOE of floating technologies; however, this is the first study, in the opinion of the authors, that seeks to evaluate the benefits created by the integration of this offshore energy. The reduction in the cost of the electricity market, due to participation in offshore generation, constitutes a starting point or reference for policy makers to establish the necessary incentives without overburdening consumers. Our findings have determined that floating offshore wind power produces a net market cost reduction of around $45 € /$ MWh of integrated offshore power. A correctly designed energy policy that seeks to promote technology development in the medium term should strike a balance between making the economic stimulus sufficiently interesting to attract investments, without creating unnecessary expenses. The merit-order effect of renewable energies can serve as a basis to stimulate a technology beyond research projects and develop it commercially. The aforementioned savings, together with the price of the day-ahead electricity market, would reach around $95 € / \mathrm{MWh}$. Regardless of whether a regulatory framework is based on premiums or CfDs auctions, having a measure of the economic impact of such technology on the market and the benefits for consumers constitutes a guide for regulators, enabling them to adjust the energy policy framework accordingly.

Future studies can focus on assessing the ability of future offshore generation to decarbonize the market. Using the data and the method developed in this work, it will be possible to quantify how many emission-producing generation units will be replaced. The introduction of offshore renewable energy replaces generation units at the top of the generation curve. Some of these marginal generation units should be thermal units (coal and gas), as these have the highest production costs and therefore, offer their energy at higher prices. A thorough identification of which units are displaced by the entry of offshore production would provide a measure of the decarbonization capacity of offshore generation.

Author Contributions: Conceptualization, J.-M.R.-F. and M.B.-P.; methodology, J.-M.R.-F. and J.S.-G.; validation, J.-M.R.-F., J.S.-G.; investigation, J.-M.R.-F. and M.B.-P.; data curation, J.-M.R.-F. and F.G.-L.; writing-original draft preparation, J.-M.R.-F.; writing-review and editing, M.B.-P., J.S.-G. and F.G.-L.; visualization, J.-M.R.-F.; supervision, M.B.-P. and J.S.-G. All authors have read and agreed to the published version of the manuscript.

Funding: CERVERA research programme of CDTI (Industrial and Technological Development Centre of Spain) under the research Project HySGrid + (CER-20191019).

Institutional Review Board Statement: Not applicable.

Acknowledgments: This work was partially supported by the Spanish MEC-Ministerio de Economía y Competitividad (Ministry of Economy and Competitiveness), co-funded by the European Commission (ERDF-European Regional Development Fund) under grant ENE2016-77650-R, the 2020 PAIDI plan, managed by the Consejeria de Economia y Conocimiento within the EU-FEDER Andalusia 2014-20 programme (project S2V, US-1265887) and the CYTED Network Programme under grant 718RT0564.

Conflicts of Interest: The authors declare no conflict of interest.

\section{References}

1. European Strategic Energy Technology Plan. Available online: https://ec.europa.eu/energy/topics/technology-and-innovation/ strategic-energy-technology-plan_en\#set-plan-information-system (accessed on 10 June 2021).

2. European Green Deal. Available online: https://ec.europa.eu/info/strategy/priorities-2019-2024/european-green-deal_en (accessed on 10 June 2021).

3. Sectorial Agenda of The Wind Industry. Available online: https://www.aeeolica.org/images/Publicaciones/Agenda-Sectorial_ Industria_Eolica_2019.pdf (accessed on 10 June 2021). 
4. Our Energy, Our Future. November 2019. How Offshore Wind Will Help Europe Go Carbon-Neutral. Available online: https://windeurope.org/intelligence-platform/product/our-energy-our-future/ (accessed on 10 June 2021).

5. Soares-Ramos, E.P.P.; de Oliveira-Assis, L.; Sarrias-Mena, R.; Fernández-Ramírez, L.M. Current status and future trends of offshore wind power in Europe. Energy 2020, 202, 117787. [CrossRef]

6. Colmenar-Santos, A.; Perera-Perez, J.; Borge-Diez, D.; de Palacio-Rodríguez, C. Offshore wind energy: A review of the current status, challenges and future development in Spain. Renew. Sustain. Energy Rev. 2016, 64, 1-18. [CrossRef]

7. Boosting Offshore Renewable Energy. Available online: https://ec.europa.eu/commission/presscorner/api/files/document/ print/en/ip_20_2096/IP_20_2096_EN.pdf (accessed on 10 June 2021).

8. European Commission. National Energy and Climate Plans. Available online: https://ec.europa.eu/info/energy-climatechange-environment/implementation-eu-countries/energy-and-climate-governance-and-reporting/national-energy-andclimate-plans_en (accessed on 10 June 2021).

9. AEE (Spanish Wind Association). Publication of Key Elements and Proposals for the Development of Offshore Wind in Spain. An Energy, Industrial and Innovation Opportunity. Elementos Clave y Propuestas para el Desarrollo de la Eólica Marina en España. Available online: https:/ /www.aeeolica.org/images/Posicionamientos/Elementos-clave-para-elica-marinaDIC2019.pdf (accessed on 10 June 2021).

10. Analysis of The Wind Resource. Technical Study Period 2011-2020. IDAE. Wind Atlas. Available online: https:/ /www.idae.es / uploads/documentos/documentos_11227_e4_atlas_eolico_A_9b90ff10.pdf (accessed on 10 June 2021).

11. Navantia. Available online: https://www.navantia.es/en/products-and-services/wind-power/floating-marine-wind/ (accessed on 10 June 2021).

12. ELICAN. A Project Supported by the European Commission H2020 Programme. 2016. Available online: https://www.esteyco. $\mathrm{com} /$ projects/elican/ (accessed on 10 June 2021).

13. Ministry of Science, Innovation and Universities, Spanish Government. Singular Technical Infrastructures. 2020. Available online: https:/ / www.ciencia.gob.es/stfls/MICINN/Investigacion/FICHEROS/ICTS_ES_ED2019.pdf (accessed on 10 June 2021).

14. European Commission. Next Generation EU. Recovery Plan. Available online: https://ec.europa.eu/info/strategy/recoveryplan-europe_en (accessed on 10 June 2021).

15. Ministry of Economic Affairs and Digital Transformation. Recovery, Transformation and Resilience Plan for the Spanish Economy. October 2020. Available online: https://www.mineco.gob.es/stfls/mineco/comun/pdf/201015_des_recovery.pdf (accessed on 10 June 2021).

16. Iberdrola. Next Generation EU. Available online: https://www.iberdrola.com/about-us/next-generation-eu (accessed on 10 June 2021).

17. European Institute of Innovation \& Technology (EIT) InnoEnergy. The Iberian Region as a Hub for Technology Development and Industrial Leadership in the Field of Floating Offshore Wind. 2020. Available online: https://info.innoenergy.com/eitinnoenergy-iberian-floating-offshore-wind-report (accessed on 10 June 2021).

18. Ryndzionek, R.; Sienkiewicz, Ł. Evolution of the HVDC Link Connecting Offshore Wind Farms to Onshore Power Systems. Energies 2020, 13, 1914. [CrossRef]

19. Díaz, C.H. Guedes Soares, Review of the current status, technology and future trends of offshore wind farms. Ocean. Eng. 2020, 209, 107381. [CrossRef]

20. Díaz, C.H.; Guedes Soares, C. An integrated GIS approach for site selection of floating offshore wind farms in the Atlantic continental European coastline. Renew. Sustain. Energy Rev. 2020, 134, 110328. [CrossRef]

21. Castro-Santos, L.; Martins, E.; Guedes Soares, C. Methodology to Calculate the Costs of a Floating Offshore Renewable Energy. Farm. Energies 2016, 9, 324. [CrossRef]

22. Myhr, A.; Bjerkseter, C.; Ågotnes, A.; Nygaard, T.A. Levelised cost of energy for offshore floating wind turbines in a life cycle perspective. Renew. Energy 2014, 66, 714-728. [CrossRef]

23. Castro-Santos, L.; Silva, D.; Bento, A.R.; Salvacao, N.; Soares, C.G. Economic feasibility of floating offshore wind farms in Portugal. Ocean. Eng. 2020, 207, 107393. [CrossRef]

24. Cummins, V.; McKeogh, E. (Eds.) Blueprint for Offshore Wind in Ireland 2020-2050: A Research Synthesis; EirWind Project; MaREI Centre, ERI, University College Cork: Cork, Ireland, 2020. [CrossRef]

25. Castro-Santos, L.; Bento, A.R.; Silva, D.; Salvação, N.; Guedes Soares, C. Economic Feasibility of Floating Offshore Wind Farms in the North of Spain. J. Mar. Sci. Eng. 2020, 8, 58. [CrossRef]

26. Real Decree 960/2020, 3 November 2020, Which Regulates the Economic Regime of Renewable Energy for Electricity Production Facilities. Available online: https:/ / www.boe.es/buscar/doc.php?id=BOE-A-2020-13591 (accessed on 10 June 2021).

27. Resolution of 26 January 2021, General Directorate of Energy Policy and Mines, First Auction Held for the Economic Regime of Renewable Energies, Order TED/1161/2020, 4 December. Available online: https:/ / www.boe.es /diario_boe/txt.php?id=BOE-A2021-1251 (accessed on 10 June 2021).

28. Sensfuß, F.; Ragwitz, M.; Genoese, M. The merit-order effect: A detailed analysis of the price effect of renewable electricity generation on spot market prices in Germany. Energy Policy 2008, 36, 3086-3094. [CrossRef]

29. Burgos-Payán, M.; Roldán-Fernández, J.M.; Trigo-García, Á.L.; Bermúdez-Ríos, J.M.; Riquelme-Santos, J.M. Costs and benefits of the renewable production of electricity in Spain. Energy Policy 2013, 56, 259-270. [CrossRef] 
30. Fernandez, J.M.R.; Payán, M.B.; Santos, J.M.R.; García, Á.L.T. Renewable generation versus demand-side management. A comparison for the Spanish market. Energy Policy 2016, 96, 458-470. [CrossRef]

31. Loumakis, S.; Giannini, E.; Maroulis, Z. Merit Order Effect Modeling: The Case of the Hellenic Electricity Market. Energies 2019, 12, 3869. [CrossRef]

32. Global Wind Atlas. Available online: https:/ /globalwindatlas.info/ (accessed on 10 June 2021).

33. OMIE. Iberian Market Operator of Electricity. Energy Files. Available online: https://www.omie.es/es/file-access-list (accessed on 10 June 2021).

34. Strategic Environmental Study of the Spanish Coast for Offshore Wind Farms. Estudio Estratégico Ambiental del Litoral Español Para la Instalación de Parques Eólicos Marinos. Available online: https:/ /www.aeeolica.org/uploads/documents/562-estudioestrategico-ambiental-del-litoral-espanol-para-la-instalacion-de-parques-eolicos-marinos_mityc.pdf (accessed on 10 June 2021).

35. Forecast, Real Time Weather and Climate, State Ports (Puertos del Estado). Available online: http://www.puertos.es/en-us/ oceanografia/Pages/portus.aspx (accessed on 10 June 2021).

36. Märkle-Huß, J.; Feuerriegel, S.; Neumann, D. Large-scale demand response and its implications for spot prices, load and policies: Insights from the German-Austrian electricity market. Appl. Energy 2018, 210, 1290-1298. [CrossRef]

37. Roldan-Fernandez, J.M.; Burgos-Payan, M.; Riquelme-Santos, J.M.; Trigo-Garcia, A.L. The Merit-Order Effect of Energy Efficiency. Energy Procedia 2016, 106, 175-184. [CrossRef]

38. Ciarreta, A.; Espinosa, M.P.; Pizarro-Irizar, C. Is green energy expensive? Empirical evidence from the Spanish electricity market. Energy Policy 2014, 69, 205-215. [CrossRef]

39. Jelle, B.P.; Breivik, C.; Røkenes, H.D. Impact of domestic PV systems in the day-ahead Iberian electricity market. Sol. Energy 2021, 217, 15-24. [CrossRef]

40. Roldan-Fernandez, J.M.; Burgos-Payan, M.; Riquelme-Santos, J.M.; Trigo-Garcia, A.L. Renewables versus Efficiency: A Comparison for Spain. Energy Procedia 2016, 106, 14-23. [CrossRef]

41. Spanish Electricity System 2019 Report. July 2020. Available online: https://www.ree.es/en/datos/publications/annual-systemreport (accessed on 10 June 2021).

42. Vestas V164-8.0. Available online: https:/ / en.wind-turbine-models.com/turbines/318-vestas-v164-8.0 (accessed on 10 June 2021).

43. Offshore Wind in Europe-Key Trends and Statistics. 2019. Available online: https://windeurope.org/wp-content/uploads/ files/about-wind/statistics/WindEurope-Annual-Offshore-Statistics-2019.pdf (accessed on 10 June 2021).

44. Graabak, I.; Korpås, M. Variability Characteristics of European Wind and Solar Power Resources-A Review. Energies 2016, 9, 449. [CrossRef] 